\title{
PERCEPÇÃO DE PRODUTORES RURAIS SOBRE OS IMPACTOS AMBIENTAIS PROVOCADOS PELAS ATIVIDADES AGROPECUÁRIAS NO MUNICÍPIO DE GUANAMBI-BAHIA
}

\author{
Solimara Ramos Mendes ${ }^{1}$, Juliane dos Santos Amorim ${ }^{2}$ e Eduarda Mendes \\ Malheiros ${ }^{3}$
}

\begin{abstract}
Resumo: O presente trabalho teve como objetivo investigar o conhecimento dos produtores rurais acerca dos impactos que as atividades agropecuárias podem causar nas áreas do entorno da Serra dos Montes Altos, município de Guanambi-BA, enfocando suas preocupações e ações sobre o manejo e conservação dos biomas ali presentes. A metodologia fundamentou-se na percepção dos impactos ambientais, tendo como suporte o método de contato individual através de um questionário subdividido em três dimensões: perfil do produtor e da área estudada; impactos das atividades agropecuárias no meio ambiente; relação manejo/conservação/preservação dos biomas, Cerrado e Caatinga. Para a avaliação das dimensões foi utilizado o método da análise do conteúdo, que consiste em analisar as falas dos sujeitos em um processo de descrição do conteúdo, além do método de porcentagem, que consiste em agrupar as informações através da similaridade. A análise dos dados permitiu indicar um grau significativo de conhecimento dos produtores sobre a importância da preservação ambiental, no entanto, a maioria desconhece os danos que as atividades agropecuárias podem gerar ao meio ambiente. Assim, faz-se necessária, a implementação de políticas educativas com esses produtores a fim de norteá-los para o uso dos recursos naturais de forma a não comprometer a qualidade ambiental da área.
\end{abstract}

Palavras-chave: Meio ambiente. Diagnóstico. Conhecimento. Ser humano.

\section{Introdução}

Desde a década de 60 , quando a sociedade passou a ter conhecimento sobre os impactos das atividades humanas, existe uma preocupação sobre a relação que o ser humano estabelece com o meio ambiente, pois em suas ações ele expressa uma capacidade de transformação e intervenção com a natureza, que implica em consequências, muitas vezes agravantes ao meio ambiente (OLIVEIRA, 2012).

Dentro deste contexto, fica evidente a relação entre o ser humano e a natureza, que desde os primórdios foi sustentada pela utilização dos recursos naturais para suprir suas necessidades diárias (MARIANO et al., 2011). À medida que a intervenção humana cresce sobre a natureza, conflitos sobre o uso dos recursos e dos espaços tendem a ganhar grandes proporções, pois o ser humano evidencia em suas ações sua capacidade de transformar o meio ambiente, mostrando seu poder de dominação sobre a natureza, pois neste processo de apropriação dos recursos naturais, o indivíduo através do processo do trabalho imprime uma exploração ilimitada de espaços e recursos naturais afetando o ambiente como um todo, o que leva a sua autodestruição, pois fazemos parte da natureza, como descreve Brito (2009), "É dela que surge o homem e pela qual ele vive".

Em âmbitos legais a Constituição Federal de 1988 traz no artigo 225 que valida ao ser humano o uso do meio ambiente, porém para tanto, é necessário que exista um limite no uso dos recursos naturais com ações compatíveis com a preservação e conservação ambiental. Contudo, a atual situação ambiental está pautada nos grandes impactos que as ações humanas têm gerado ao longo dos anos, e dentre as atividades de destaque estão as ligadas ao setor agropecuário, que se intensifica e provoca sérios danos ao ambiente, devido à alta necessidade dos recursos naturais. Isso tem

\footnotetext{
1E-mail: mharamendes@hotmail.com

²E-mail: juliane_jsa@hotmail.com

${ }^{3}$ E-mail: eduarda_mallheiros@hotmail.com
} 


\section{REA - Revista de estudos ambientais (Online) v.21, n. 2, p.6-19, jul./dez. 2019}

gerando inúmeros desafios, uma vez que, o individuo tem que garantir a produtividade no setor agropecuário e ao mesmo tempo reduzir os impactos de suas produções no meio ambiente (SAMBUICHI et al., 2012).

Nessa perspectiva, por meio da agricultura e da pecuária, o ser humano faz do campo um meio propício para 0 desenvolvimento de práticas que subsidiem sua existência que ao longo dos anos tem gerado alterações, na maioria das vezes negativas no meio ambiente.

O setor agropecuário apresenta grande expressividade no cenário comercial em nosso país, gerando uma prática de utilização dos recursos naturais, que por decorrência causam os impactos ambientais que afetam significativamente as relações ecológicas dos seres vivos, o ciclo hidrológico, o clima e a qualidade dos recursos naturais. Assim, é imprescindível que a garantia da conservação das riquezas naturais seja estabelecida, do mesmo modo a melhoria das condições de vida da sociedade, bem como para o individuo que trabalha no campo, que lida diariamente com os desafios presentes entre produto/preservação (SAMBUICHI et al., 2012).

Em meio a isso, a ação humana na obtenção dos recursos naturais não tem dado o tempo geológico necessário para que a natureza se recomponha e minimize os graves problemas ambientais que estamos evidenciando. Estes problemas foram gerados ao longo da história da humanidade, pois o processo evolutivo mudou os hábitos do ser humano, que há poucos séculos desenvolveu a prática do cultivo de vegetais, domesticação e a criação de animais (MORIMOTO; SALVI, 2009), que por ventura tem gerado grandes transformações nas paisagens naturais, principalmente nos biomas de Caatinga e Cerrado.

O uso sustentável e a conservação dos recursos naturais dos biomas de Caatinga, tal como do Cerrado são de extrema preocupação, devido à forma de uso e ocupação dessas regiões, pois em proporção a seu território, são considerados os biomas mais explorados e degradados do mundo (MOREIRA; LIRA; SANTOS, 2006), principalmente por atividades ligadas à ação humana, no que se refere ao uso da terra (CAMPOS, 2012).

O Cerrado no território nacional está comumente associado com a Caatinga originando áreas de ecótonos com grande representatividade de fisionomias vegetais, comunidades de animais e tipos de solo, contribuindo para uma elevada riqueza de espécies (SILVEIRA, 2010). Mesmo assim, existe um índice de exploração dos recursos naturais desses biomas desde a colonização do Brasil (GARIGLIO et al., 2010), e com o processo de ocupação dessas terras, a interferência antrópica foi ao longo dos anos ganhando notoriedade, o que potencializou o uso da terra para os fins agropecuários.

$\mathrm{Na}$ região semiárida do Nordeste brasileiro a monocultura, comumente utilizada pelo pequeno produtor, é fonte de renda de muitas famílias, no entanto, tende a contribuir com a perda da qualidade do solo, que muitas vezes intensifica a abertura de novas áreas para a produção, ora por desmatamento, ora por queimadas, gerando perdas incalculáveis ao meio ambiente (LEITE; SILVA; HENRIQUES, 2011; MELO et al., 2013). Em muitos casos na execução dessa prática, não se aplica uma Avaliação de Impacto Ambiental (AIA) sobre as atividades desenvolvidas, o que negligência a forma com que as atividades são desenvolvidas (MATTOS DE DEUS; BAKONYI, 2012).

Nesse contexto, a educação ambiental (EA) se torna uma aliada às práticas voltadas para a promoção do conhecimento e de ações que minimizem os efeitos que as atividades agropecuárias causam ao meio ambiente. $O$ desenvolvimento é extremamente necessário para a humanidade, que a todo momento, usufrui dos mais variados recursos naturais, porém a $E A$, tem procurado moldar o saber ambiental numa perspectiva educativa, que procura promover na comunidade, posturas voltadas para o uso consciente dos recursos, além de atitudes e valores que visem o desenvolvimento sustentável (FERREIRA, 2007).

Assim, o processo de construção de novos modelos de relação natureza/homem é de extrema importância na formação de uma postura positiva do individuo frente às questões ambientais, inserindo a educação como uma medida transformadora e construtiva de relações socioambientais na participação sustentável do planeta, em que a cidadania seja uma vertente norteadora dos atos de preservação dos ambientes (QUADROS, 2007; REIGOTA, 2009).

É valido promover ações que visem à conscientização dos produtores rurais e de todos aqueles que estão direta e indiretamente relacionados com as atividades agropecuárias, sobre os prejuízos que essas práticas podem causar ao meio ambiente, 


\section{REA - Revista de estudos ambientais (Online) v.21, n. 2, p.6-19, jul./dez. 2019}

mostrando alternativas que podem diminuir os impactos, pois as explorações agrícolas e a pecuária quando devidamente planejadas, aliada à alternativas que minimizem os impactos gerados, são de grande valia para a manutenção dos ecossistemas (ARAUJO, 2010), uma vez que, os produtos oriundos do campo são de suma importância para a vida das pessoas e para o mercado mundial, sendo indispensáveis para o desenvolvimento do país (AZEVEDO; SILVA, 2015), pois o ser humano é parte fundamental desse contexto, como agente modelador e transformador da natureza.

Buscar o entendimento da percepção ambiental é um dos objetivos dos trabalhos realizados sobre a interação do ser humano com o espaço e toda a dinâmica estabelecida nesse contexto (OLIVEIRA; MACHADO, 2004). A percepção é um meio pela qual o indivíduo toma consciência e compreende o ambiente, na melhoria de suas condições de vida, assim, a percepção ambiental funciona como uma ferramenta indispensável na busca pela preservação e conservação dos recursos naturais e seus ambientes, registrando a forma com que o indivíduo percebe e descreve sua relação com o meio em que vive (LUCENA, 2010). Diante disso, esse trabalho teve por objetivo investigar o conhecimento que os proprietários rurais têm sobre os impactos causados ao meio ambiente a partir das atividades rurais em áreas do entorno da Serra dos Montes Altos no município de Guanambi-BA.

\section{Metodologia}

A pesquisa foi realizada com agropecuaristas do entorno do Parque Estadual da Serra dos Montes Altos - PESMA (Decreto № 12.486 de 2010), restringindo-se a área que pertence ao município de Guanambi/Ba.

O Parque Estadual está localizado na região sudoeste da Bahia (14²8'31"S $42^{\circ} 58^{\prime} 46^{\prime \prime} \mathrm{O}$ ), abrangendo parte dos municípios de Palmas de Monte Alto, Sebastião Laranjeiras, Urandi, Guanambi (distrito de Mutans), Pindaí e Candiba. Sua elevação abrange parte da Serra do Espinhaço (SEMA, 2011; TASSO; CHANG, 2013) e apresenta abrangência de 90 mil hectares distribuídos em $60 \mathrm{~km}$ de extensão, sendo a maior largura de $20 \mathrm{~km}$ (SEMA, 2011). A altitude média do parque é de $900 \mathrm{~m}$, e a maior elevação atinge $1315 \mathrm{~m}$ (NOGUEIRA, 2014). O parque está situado em uma região semiárida, compreendendo os biomas Cerrado e Caatinga (VELOSO; RANGEL FILHO; LIMA, 1991), onde temperaturas altas predominam o ano todo, variando entre 23 e $27^{\circ} \mathrm{C}$, com precipitação média anual inferior a $800 \mathrm{~mm}$ (MARENGO, 2008).

A pesquisa foi de caráter intencional, realizada através do levantamento de dados das comunidades e principalmente dos produtores rurais que possuem propriedades situadas nas proximidades da Serra dos Montes Altos e que realizam atividades rurais ligadas à agropecuária. A coleta de dados foi realizada com os moradores maiores de 18 anos que demostraram interesse $e$ disponibilidade em responder o questionário, sendo este o objeto de contribuição direta do estudo.

O questionário contou com 38 perguntas, subdividido em três dimensões: perfil do produtor, aspectos sobre a área, as atividades e as técnicas desenvolvidas por eles em suas propriedades; conhecimento sobre os impactos de suas atividades agropecuárias no meio ambiente; relação manejo/conservação dos recursos naturais e preservação dos biomas, Cerrado e Caatinga. Os questionários foram aplicados nos meses de abril e maio do ano de 2017 a 20 produtores rurais, que dentre os 28 produtores identificados no entorno do Parque Estadual da Serra dos Montes Altos na área do município de Guanambi-Ba aceitaram responder ao questionário, correspondendo a/ 71,5\% do total.

Os questionários foram analisados em primeira instância de forma individual para uma melhor compreensão e descrição dos dados, seguido de uma análise mais detalhada de acordo com as dimensões de variáveis de pesquisa, adaptadas de Whyte (1977, apud LUCENA, 2010).

DIMENSÃO 1 - Variáveis de estado: perfil do produtor, aspectos sobre a área, as atividades e as técnicas desenvolvidas por eles em suas propriedades. DIMENSÃO 2 Variáveis de saída: conhecimento sobre os impactos de suas atividades agropecuárias no meio ambiente. DIMENSÃO 3 - Processos de percepção: relação manejo/conservação dos recursos naturais e preservação dos biomas, Cerrado e Caatinga.

Para a avaliação das dimensões nas questões subjetivas, foi utilizado o método da análise do conteúdo, fundamentado por Bardin (2009), que consiste em analisar as falas dos sujeitos em um processo de descrição do conteúdo das mensagens. Para 


\section{REA - Revista de estudos ambientais (Online) \\ v.21, n. 2, p.6-19, jul./dez. 2019}

tal foi utilizado um código para determinar os produtores rurais que participaram da pesquisa de acordo com a ordem da aplicação dos questionários - P: Produtores rurais; 1 a 20: ordem de aplicação dos questionários.

Nas questões objetivas, foi utilizada uma análise simples (porcentagem) que consiste em agrupar as informações, podendo mensurar os dados a partir de uma similaridade de um mesmo grupo quando comparadas entre si. Para a tabulação dos dados, montagem de gráficos e demais cálculos percentuais foi utilizado o programa Microsoft Office Excel 2010.

Seguindo esses parâmetros os resultados foram descritos e discutidos com bases em trabalhos de ordem cientifica, direcionados, a relação ser humano/natureza, aos impactos das atividades agropecuárias no ambiente, os conhecimentos que permeia a sociedade no que se referem à preservação, manejo e conservação dos ambientes naturais, mais especificadamente nos biomas Cerrado e Caatinga, além dos discursos pautados no contexto da educação ambiental.

\section{Resultados}

\subsection{Dimensão 1 - Variáveis de Estado}

Em meio aos 20 entrevistados a maioria foi do sexo masculino (65\%), cuja idade variou entre 39 e 74 anos, com média de 62 anos. A idade do sexo feminino variou de 31 a 64 anos, com média de 46 anos. Quanto ao estado civil, $90 \%$ são casados, $5 \%$ divorciados e $5 \%$ viúvos. No que diz respeito ao grau de escolaridade, $90 \%$ apresenta escolaridade, que vai do nível fundamental ao superior completo, desses 30\% cursaram até a $4^{\mathrm{a}}$ série (4 $\left.\mathrm{ano}\right)$ do fundamental I, $30 \%$ possuem ensino médio completo, $20 \%$ o fundamental II completo e $10 \%$ nível superior completo (Figura 1). Ao se comparar com o censo do ano de 2006 pode-se notar que o nível de escolarização dos produtores rurais pode estar sofrendo mudanças significativamente positivas, pois o censo de 2006 apresenta o dado de $81,4 \%$ com o nível de escolaridade do fundamental I incompleto ou menos em nível de Brasil e em relação a região Nordeste $30,2 \%$ para essa categoria (IBGE, 2006).

Figura 1 - Grau de escolaridade dos produtores rurais

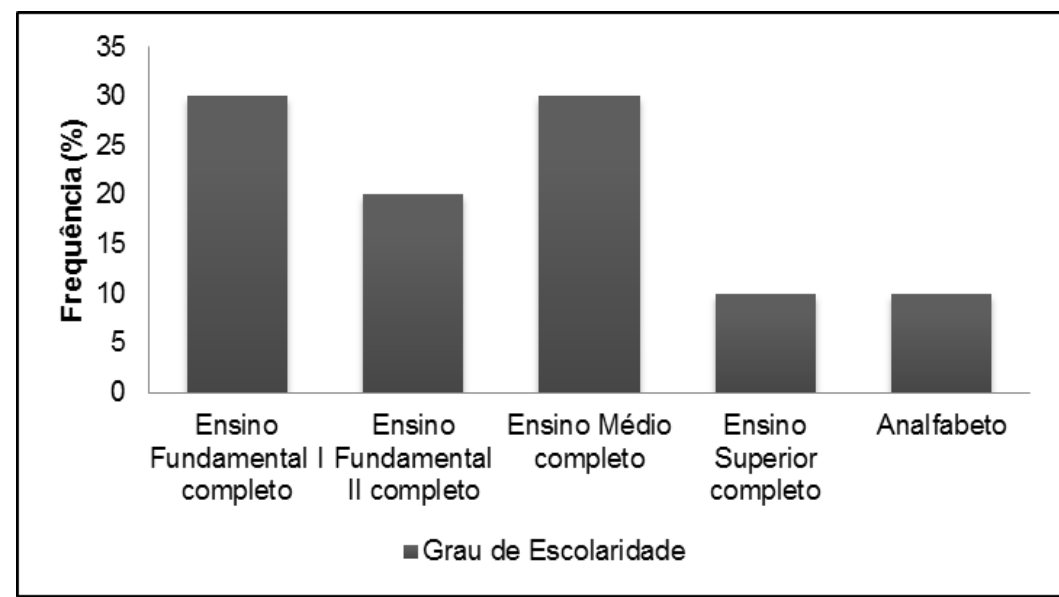

Fonte: Autoras (2019)

Em relação ao tempo de trabalho no campo, teve uma variação de 15 a 65 anos. $100 \%$ dos entrevistados nasceram na zona rural, no entanto, $50 \%$ se mudaram para o distrito de Mutãs, e os demais $50 \%$ ainda residem em suas propriedades rurais.

A região Nordeste tem sido marcada pelo aumento da migração do campo para a cidade, que pode estar associado a questões sociais, econômicas, culturais, políticas e ambientais, que podem interferir em melhores condições de vida (SANTOS; SILVA;
OLIVEIRA, 2009; CASAGRANDE; SOUZA, 2012), no entanto, a partir dos dados acima pode-se perceber que os produtores em questão, mesmo migrando para a área urbana ainda se mantem vinculado ao meio rural.

As propriedades pesquisadas apresentam tamanhos que variam de 2 a 50 hectares, sendo que esse dado mostra que esses produtores se encaixam nos dados do SEBRAE que apontam que $90 \%$ dos produtos do Brasil são provenientes de propriedades 


\section{REA - Revista de estudos ambientais (Online) v.21, n. 2, p.6-19, jul./dez. 2019}

com área inferior a 100 hectares, apresentando o predomínio de propriedades pequenas. Neste contexto também há um destaque da região Nordeste que apresenta uma expressividade no número de propriedades com áreas menores que 100 hectares (IBGE, 2006).

No que se refere à vegetação nativa do terreno foi perguntado aos produtores que tipo de vegetação era vista com mais abundância em seu terreno, sendo que $90 \%$ responderam Cerrado, $5 \%$ Caatinga e 5\% não sabiam dizer; esses dados mostram que os produtores conseguem determinar a vegetação da região, mesmo o percentual sendo baixo para a Caatinga se nota que eles têm conhecimento para identificá-la, pois essas afirmações são verdadeiras, visto que, a vegetação da região varia de Caatinga, Caatinga arbórea, Cerrado, Campos rupestres e Matas de galeria (INEMA, 2017).

Em relação à presença de recurso hídrico foi verificado que existem propriedades com presença de nascentes, que são utilizadas como recurso natural para as produções agropecuárias, apresentando um resultado de $35 \%$ dos produtores com essa riqueza natural em seus terrenos, já os demais $65 \%$ dos produtores buscaram alternativas para a obtenção de água em suas propriedades como, a abertura de poços artesianos. Esse dado confirma a abundância hídrica da região que possui um número considerável de nascentes e águas subterrâneas, fator importante para as comunidades de seres vivos ali existentes, além de possibilitar o abastecimento dos municípios próximos. Existem dois grandes cursos d’água que fazem parte da Serra dos Montes Altos, o rio Casa Velha ou Curralinho e o rio Mandiroba (TASSO, 2012).

Foi observado que $60 \%$ dos produtores destinam uma área que vai de 50 a $100 \%$ de seu terreno para a produção que está ligada a agricultura e/ou pecuária, e que $40 \%$ destinam uma área inferior a $50 \%$ de seu terreno. Dos produtores entrevistados 65\% deles destina sua produção para a pecuária e agricultura, 25\% apenas para a agricultura e $10 \%$ somente para a pecuária (Figura 2). Pode-se assim perceber que a maioria desenvolve suas produções no setor agropecuário, o que pode ser explicado com base no clima da região semiárida que é marcado pela variabilidade espaço-temporal e na maior parte do ano se encontra quente e seco, apresentando períodos de chuva que varia de outubro/março (LEAL et al., 2005). Esses dados corroboram com os dados obtidos por Pereira (2007), em que a prática da agropecuária teve também maior expressividade.

Diante disso, os produtores têm que manter sua produtividade durante o ano todo, optando pela pecuária e agricultura para estabelecer o equilíbrio produtivo durante o período de seca e o chuvoso, respeitando a sazonalidade de cada produção. Atrelado a isso se tem os dados sobre o período de maior produção, em que $83,4 \%$ dos agricultores apresentam o maior número de produção em épocas chuvosas e 16,6\% em épocas de seca.

Figura 2 - Opção produtiva dos produtores rurais

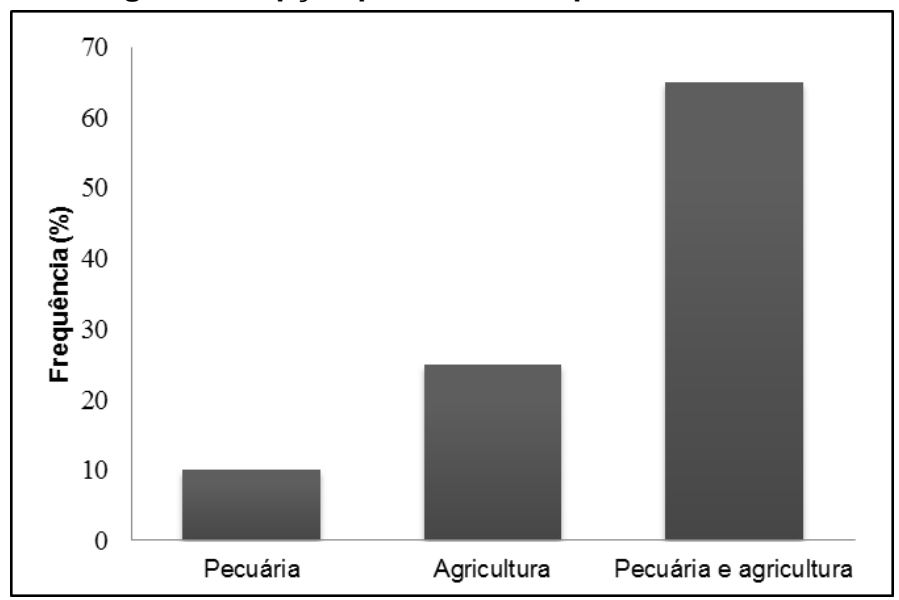

Fonte: Autoras (2019)

As produções destinadas à pecuária estão voltadas para a criação de bovinos, caprinos, suínos, aves, equinos e ovinos (Tabela 1), podendo-se notar que a produção 


\section{REA - Revista de estudos ambientais (Online)}

v.21, n. 2, p.6-19, jul./dez. 2019

mais citada foi a de bovinos, o que se dá devido à facilidade na criação de animais com pasto, se tornando mais viável economicamente, pois há uma facilidade na prática de produzir e oferecer alimentos para os bovinos (DIAS-FILHO, 2010).

Já para o desenvolvimento da agricultura os itens mais citados foram milho, feijão e sorgo (Tabela 2), devido às diversas formas de utilização, que vai desde a alimentação de animais até o setor industrial. O milho em grão possui grande expressividade no território nacional, no que diz respeito à alimentação de animais, com um consumo que varia de 70 a $90 \%$ a depender da região geográfica (CRUZ et al., 2011)

Em relação ao destino das produções os agropecuaristas disseram que utilizam tanto para o consumo quanto para a comercialização, sendo que $40 \%$ deles destinam sua produção para o próprio consumo, mesmo percentual daqueles que utilizam tanto para o próprio consumo quanto para a comercialização (Figura 3). Ainda foi averiguado que $95 \%$ da produção é comercializada no próprio município em feiras-livres. Muitos dos agropecuaristas são aposentados, mas permanecem trabalhando na agricultura e na pecuária para ampliar a renda e garantir a subsistência.

No preparo do terreno para a produção, a maioria citou que utiliza o corte para a limpeza do terreno, com um percentual de $55 \%$ de citações (Figura 4), mostrando que a maioria dos produtores busca uma alternativa menos devastadora, o corte da vegetação, invés da prática da queimada (apenas 10\% dos entrevistados utilizam essa ferramenta), que provoca sérios danos ao ambiente, como a destruição de microrganismos do solo, da matéria orgânica, além de aumentar o processo erosivo (ARF; BOLONHEZI, 2012).

Tabela 1 - Pecuária desenvolvida pelos produtores rurais do entorno do Parque Estadual da Serra dos Montes Altos, Guanambi-BA, 2017

\begin{tabular}{l|c|c}
\hline \multicolumn{1}{c|}{ Pecuária desenvolvida } & $\mathbf{N}^{\circ}$ de citações & Percentual (\%) \\
\hline Bovinos & 13 & 40 \\
Suínos & 5 & 15 \\
Ovinos & 4 & 13 \\
Aves & 4 & 13 \\
Equinos & 4 & 13 \\
Caprinos & 2 & 6 \\
\hline TOTAL & $\mathbf{3 2}$ & $\mathbf{1 0 0}$ \\
\hline
\end{tabular}

Fonte: Autoras (2019)

Tabela 2 - Agricultura desenvolvida pelos produtores rurais do entorno do Parque Estadual da Serra dos Montes Altos, Guanambi-BA, 2017

\begin{tabular}{l|c|c}
\hline \multicolumn{1}{c|}{$\begin{array}{c}\text { Agricultura } \\
\text { desenvolvida }\end{array}$} & $\mathbf{N}^{\circ}$ de citações & Percentual (\%) \\
\hline Milho & 14 & 28 \\
Feijão & 13 & 26 \\
Sorgo & 7 & 14 \\
Mandioca & 4 & 8 \\
Palma & 3 & 6 \\
Capim & 3 & 6 \\
Algodão & 2 & 4 \\
Cana-de-açúcar & 1 & 2 \\
Coco & 1 & 2 \\
Laranja & 1 & 2 \\
Outros & 1 & 2 \\
\hline TOTAL & 50 & $\mathbf{1 0 0}$ \\
\hline
\end{tabular}

Fonte: Autoras (2019) 


\section{REA - Revista de estudos ambientais (Online)}

v.21, n. 2, p.6-19, jul./dez. 2019

Figura 3 - Destino das produções dos produtores rurais do entorno do Parque Estadual da Serra dos Montes Altos, Guanambi-Ba

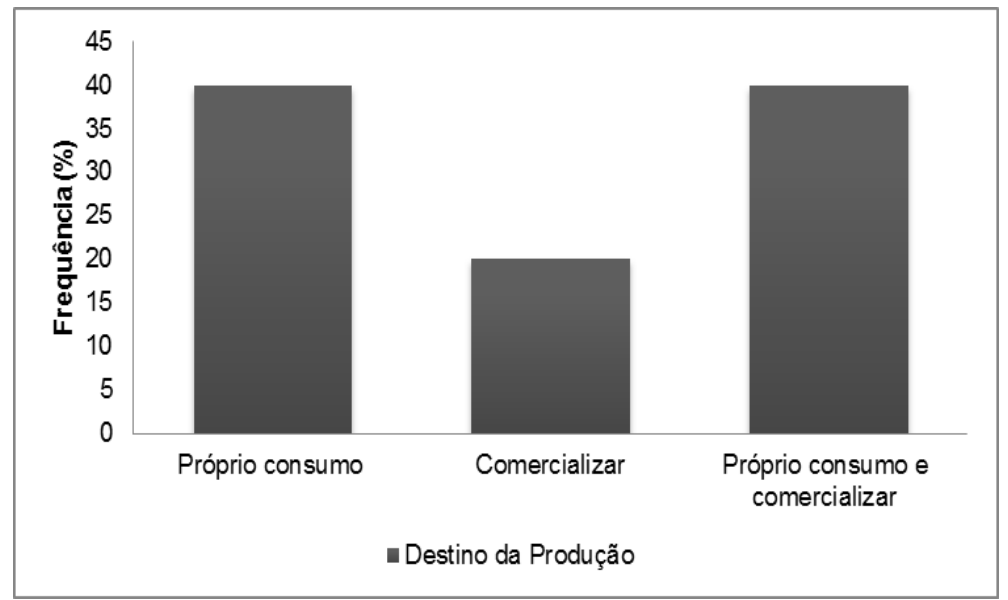

Fonte: Autoras (2019)

Figura 4 - Técnicas utilizadas pelos produtores rurais do entorno do Parque Estadual da Serra dos Montes Altos, Guanambi-Ba para a limpeza dos terrenos para a produção agropecuária

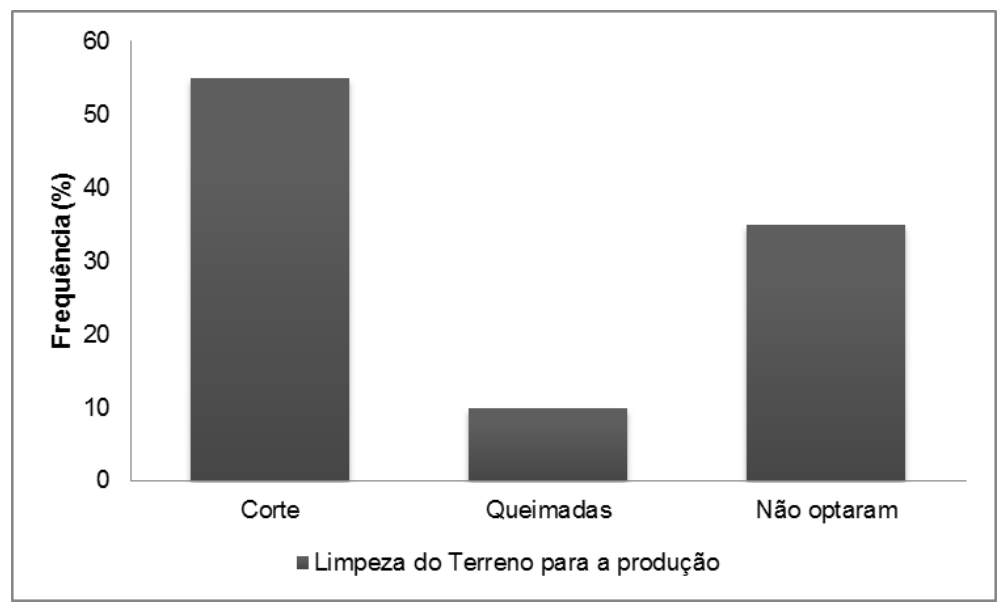

Fonte: Autoras (2019)

Quando questionados sobre o tema adubação, 85\% dos agricultores disseram que utilizam adubo. Desses, 20\% utilizam adubo orgânico e $80 \%$ faz uso tanto dos orgânicos quanto dos inorgânicos. 66,7\% fazem 0 uso de agrotóxicos em suas produções e disseram que devolvem as embalagens nos pontos de coleta (33,3\%), entregam na associação (25\%), enterram (25\%) ou queimam (16,7\%) (Figura 5). A utilização de produtos agroquímicos por muitos anos foi visto como uma alternativa eficiente no "combate a pragas" e essa prática se estendeu até a agricultura familiar, no entanto, essa ideia foi sendo modificada a medida que foi verificado que a utilização indiscriminada de agrotóxicos traz sérios riscos à saúde da população, desde o trabalhador até os consumidores dos insumos produzidos no campo, além disso também provoca grandes impactos ambientais com alterações significativas nos ecossistemas (MIRANDA, 2016).

Quando perguntados sobre a utilização da mesma área para o plantio de insumos agrícolas, $66,7 \%$ dos agricultores disseram não utilizar a mesma área para a mesma produção em anos consecutivos, utilizando a técnica de rotação de culturas. Essa técnica é uma das mais ambientalmente corretas, pois ela diminui a vulnerabilidade dos solos através da ciclagem de nutrientes (ARNHOLD; RITTER; BALBINOT, 2016). Já $33,3 \%$ disseram que não se preocupam com 


\section{REA - Revista de estudos ambientais (Online) \\ v.21, n. 2, p.6-19, jul./dez. 2019}

essa questão e sempre utilizam a mesma área para o plantio do mesmo produto, o que pode ser visto como uma alternativa inapropriada no processo de conservação da qualidade do solo levando ao processo de desertificação.

Em relação ao modo de criação de animais, $64,3 \%$ dos pecuaristas criam seus animais ora soltos, ora em curais, $28,6 \%$ apenas soltos e $7,1 \%$ citaram que depende da necessidade. $100 \%$ dos pecuaristas disseram que destinam parte de seu terreno para a pastagem dos animais, e essa área é proporcional ao tamanho do terreno de cada produtor, podendo variar, a depender da necessidade, que varia de 2 hectares para o produtor de pequeno porte a 30 hectares para o produtor de médio porte.

\section{Figura 5 - Formas de descarte das embalagens de agrotóxicos utilizadas pelos produtores rurais do entorno do Parque Estadual da Serra dos Montes Altos, Guanambi-Ba}

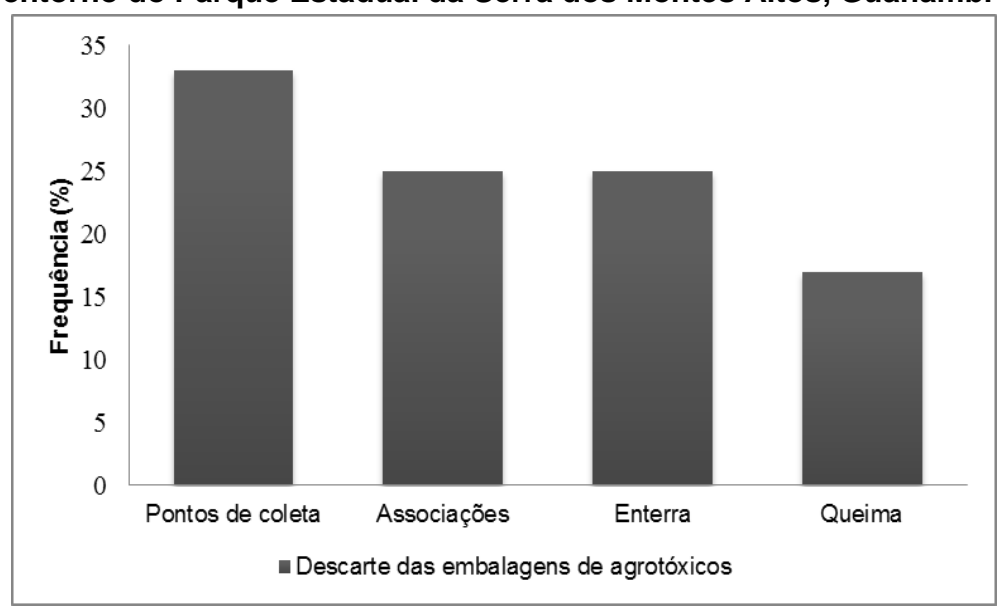

Fonte: Autoras (2019)

\subsection{Dimensão 2 - Variáveis de saída}

Ao avaliar o conhecimento dos produtores rurais a respeito do impacto que suas atividades agropecuárias podem provocar no meio ambiente, nota-se que eles estão passando por um processo de aprendizagem, no que se refere aos assuntos ambientais, visto que a maioria ainda está vinculada a ideia de que o ambiente é fonte inesgotável de recursos naturais.

Para 55\% dos entrevistados a criação de animais não geram danos ao meio ambiente, no entanto, $25 \%$ se posicionaram de forma contrária, citando alguns prejuízos como, gases poluentes, desmatamento e consumo alto de água; os demais $20 \%$ não optaram. Referente ao cultivo de vegetais, $60 \%$ dos entrevistados disseram que essa atividade não gera danos ao meio ambiente, já para $25 \%$ dos entrevistados pode sim gerar danos citando-se, desmatamento, alteração do clima, erosão e extinção de espécies; $15 \%$ não optaram.

Quando perguntados se a retirada da vegetação nativa para a agricultura ou pra fazer pasto para os animais danifica o ambiente, observou-se uma controvérsia ao se confrontar com as questões anteriores, pois $70 \%$ dos entrevistados disseram que retirar a vegetação nativa para a agricultura ou para a pastagem danifica o meio ambiente, causando impacto climático, mudança no ecossistema e extinção de espécies nativas. No entanto, houve um posicionamento contrário, quando perguntados sobre os prejuízos que a agropecuária pode causar, visto que, a maioria se manteve na negatividade dos danos.

Essas informações mostram que apesar de se ter um percentual de conhecimento a cerca dos impactos que as atividades agropecuárias causam ao ambiente, ainda se necessita de um conhecimento mais abrangente sobre os danos que a produção agropecuária pode provocar ao meio ambiente, visto o índice mais elevado para os que não sabem ou não acreditam nos impactos dessas atividades, pois é a partir do conhecimento que alternativas que minimizem esses danos são buscadas como forma de manter a qualidade de seu terreno, a saúde dos ecossistemas e a sobrevivência da humanidade. De acordo com Pereira (2007) estratégias sustentáveis podem ser a peça chave para manter o equilíbrio entre a agricultura, pecuária e meio 


\section{REA - Revista de estudos ambientais (Online) v.21, n. 2, p.6-19, jul./dez. 2019}

ambiente visando a promoção da qualidade de vida dos seres que dele dependem.

Em relação ao uso de agrotóxicos, $95 \%$ se posicionaram dizendo que o uso de agrotóxicos é maléfico ao meio ambiente, citando, danos à saúde, poluição, enfraquecimento do solo, intoxicação, inibição de crescimento da vegetação nativa, prejuízo à preservação ambiental e alteração do equilíbrio natural. Os produtores rurais geralmente possuem poucas informações sobre esses produtos, devido à falta de orientação que recebem a respeito da manipulação dos agrotóxicos, isso muitas vez está relacionado ao momento da compra, ou por falta de um técnico para a aplicação. Associado a isso pode-se citar o restrito conhecimento dos danos que a utilização desses produtos gera ao ser humano e ao ambiente, contaminando a água, o solo e os seres vivos nas mais diversas formas e os alimentos que serão consumidos por eles (PEREIRA, 2007).

Constatou-se um resultado de grande relevância para o questionamento sobre o uso extensivo do solo com um percentual de $95 \%$ dos entrevistados afirmando que o uso extensivo do solo gera danos ao meio ambiente, citando, a degradação do solo, a modificação da área, o enfraquecimento do solo.

\subsection{Dimensão 3 - Processos de Percepção}

No que concerne à percepção dos produtores rurais a respeito da preservação dos recursos naturais existentes no entorno do Parque Estadual da Serra dos Montes Altos foi verificado que há conhecimento a cerca dessa temática, vinculada aos saberes sobre o que é preservação ambiental, pois $100 \%$ das pessoas disseram que já ouviram falar em preservação ambiental, através de reuniões da associação, palestras, meios de comunicação, sindicatos, escolas, igrejas, livros, seminário do meio ambiente e orientação dos guardas florestais do Instituto do Meio Ambiente e Recursos Hídricos (INEMA). Com os depoimentos dos produtores pode-se observar que existe um grau de entendimento sobre o contexto da preservação ambiental mesmo que ainda em fase de construção:

P1. "Cuidar da natureza" / P7. "Não destruir as obras da natureza" / P12. "É preservar o ambiente, não cortar as árvores" / P15. "Uso sustentável e consciente dos recursos naturais e reposição através do reflorestamento" / P18. "Não jogar lixo, não fazer queimadas".

Mediante a construção de um conceito sobre preservação ambiental, 100\% dos entrevistados considera importante a preservação dos recursos naturais, citando:

P3. "Preservar para que não cesse estes recursos" / P4. "Precisamos dele para sobreviver" / P7. "Porque é através dos recursos naturais que podemos manter 0 equilíbrio ecológico, e uma sustentabilidade favorável" / P14. "Manter sempre os recursos na região".

Essas falas mostram que os produtores consideram a preservação ambiental algo de grande importância e a partir de seus níveis de conhecimento e experiência buscam desenvolver alternativas que minimizem os danos ambientais provocados pelas atividades agropecuárias. Essas alternativas foram citadas quando descreveram o cuidado que tem aos recursos naturais presentes em suas propriedades.

$\mathrm{P} 1$. "Mantenho as áreas de preservação intactas" / P9. "Manejo plantas nativas e conservo o solo" / P14. "Uso de forma consciente, sem exagero" / P16. "Preservo as árvores nativas, e controlo o uso de máquinas no solo".

Existe uma preocupação por parte dos entrevistados em deixar parte do seu terreno com a vegetação nativa, pois $95 \%$ dos entrevistados disseram ter essa preocupação. Mesmo se tratando de uma Unidade de Conservação (UC), esse dado mostra que os produtores percebem a importância que se deu a criação desse parque, pois se trata de uma área com uma diversidade de espécies considerável, e a sua implantação foi de fundamental importância para assegurar a conservação da biodiversidade regional. A evidência dessa preocupação demostrada na questão anterior vem atrelada a conscientização da importância que a vegetação nativa tem para a região. Pode-se verificar nas citações abaixo:

P5. "Alimentação para os animais" / P6. "Mantem o equilíbrio ecológico" / P15. "Conserva a característica do bioma e clima da região" / P19. "Preservar a natureza". 


\section{REA - Revista de estudos ambientais (Online) \\ v.21, n. 2, p.6-19, jul./dez. 2019}

Em relação às ações sobre manejo florestal, os produtores foram questionados sobre 0 que realizam a respeito dessa questão, sendo que $90 \%$ deles afirmaram ter o costume de plantar árvores em seu terreno. As árvores citadas foram: aroeira (Myracrodruon urundeuva), juazeiro (Ziziphus joazeiro), leocena (Leucaena leucocephala), ipê (Tabebuia sp.), jatobá (Hymenaea courbari), amburana macho (Amburana Cearensis) e frutíferas diversas (mangueira, laranjeira, coqueiro, pinheira, abacateiro, cajueiro, tamarindeiro, umbuzeiro, pequizeiro, pitomba). Das árvores citadas a que teve maiores expressões foram às frutíferas $77,7 \%$. Uma citação preocupante foi em relação à Leucaena leucocephala, pois se trata de uma espécie exótica com característica ruderal que ajuda no processo de recuperação de áreas degradadas, no entanto a disseminação dessa espécie em larga escala pode inibir a proliferação de espécies nativas da região, não sendo recomendada quando a meta for à recuperação da vegetação nativa da região (COSTA; DURIGAN, 2010).

Outra observação importante é o fato da expressividade das citações em relação às plantas frutíferas não nativas, que não se encaixam no processo de recuperação ou preservação dos biomas, pois se enquadram apenas no aspecto de subsistência, se tornando mais um meio de cultivo e produção.

Os produtores citaram algumas das plantas nativas presentes em seu terreno (Tabela. 3), porém mesmo conseguindo identificar algumas plantas nativas ainda apresentam 0 costume de buscar 0 reflorestamento através de árvores frutíferas não nativas.

Foi perguntado também aos entrevistados a respeito da presença de animais silvestres em suas propriedades, e $100 \%$ deles afirmaram que ela existe e desses, $80 \%$ disseram que se preocupam com a preservação das espécies de animais silvestres presentes na região. Eles citaram o nome de alguns dos animais mais visto na região (Tabela 4).

Essas informações confirmam a presença da rica diversidade de espécies que se pode encontrar nessa área, como por exemplo, o cachorro do mato também conhecido como cachorro-vinagre (Speothos venaticus), um dos motivos que possibilitaram a criação do parque, pois se trata de uma espécie ameaçada de extinção (DODONOV, 2011). Também foi constatado que há a presença de plantas classificadas como medicinais que são utilizadas no tratamento de vários problemas de saúde na medicina alternativa, advindo do conhecimento popular sobres suas funções fitoterápicas.

Mesmo se tratando de uma área de UC foi necessário saber dos produtores se em seus terrenos existe reserva florestal, e $85 \%$ dos entrevistados disseram que sim. Dos $85 \%$ que tem reserva florestal, $41,2 \%$ disseram que aumentariam sua reserva, já $58,8 \%$ disseram que não, esses se justificaram dizendo:

$\mathrm{P} 1$. "Propriedade pequena com área preservada considerável" / P3. "Porque as áreas não preservadas tem ocupação" / P17. "Porque a propriedade é pequena".

Tabela 3 - Plantas nativas identificadas em seus terrenos citadas pelos produtores rurais do entorno do Parque Estadual da Serra dos Montes Altos, Guanambi-BA

\begin{tabular}{l|l|c|c}
\multicolumn{1}{c|}{ Nome popular } & \multicolumn{1}{|c|}{ Nome científico } & No de citações & Percentual (\%) \\
\hline Juazeiro & Ziziphus joazeiro & 17 & 20,4 \\
Angico & Anadenanthera sp. & 14 & 16,9 \\
Umbuzeiro & Spondias tuberosa & 14 & 16,9 \\
Pau-d'arco & Tabebuia sp. & 9 & 10,8 \\
Jurema & Mimosa tenuiflora & 7 & 8,4 \\
Amburana macho & Amburana Cearensis & 6 & 7,2 \\
Aroeira & Myracrodruon urundeuva & 5 & 6,0 \\
Catinga de porco & Caesalpinia pyramidalis & 4 & 4,9 \\
Coco licuri & Syagrus coronata & 4 & 4,9 \\
Pitomba & Talisia esculenta & 3 & 3,6 \\
\hline TOTAL & & $\mathbf{8 3}$ & $\mathbf{1 0 0}$ \\
\hline
\end{tabular}

Fonte: Autoras (2019) 


\section{REA - Revista de estudos ambientais (Online) \\ v.21, n. 2, p.6-19, jul./dez. 2019}

Tabela 4 - Animais nativos identificados em seus terrenos citados pelos produtores rurais do entorno do Parque Estadual da Serra dos Montes Altos, Guanambi-BA

\begin{tabular}{l|c|c}
\hline \multicolumn{1}{c|}{ Nome popular } & $\mathbf{N}^{\circ}$ de citações & Percentual (\%) \\
\hline Gambá & 17 & 17,34 \\
Seriema & 14 & 14,30 \\
Veado & 14 & 14,30 \\
Tatu & 7 & 7,14 \\
Teiú & 6 & 6,12 \\
Sagui & 6 & 6,12 \\
Perdiz & 5 & 5,10 \\
Aves diversas & 5 & 5,10 \\
Preá & 4 & 4,08 \\
Raposa & 3 & 3,06 \\
Camaleão & 3 & 3,06 \\
Jacu & 3 & 3,06 \\
Cobras diversas & 3 & 3,06 \\
Macacos & 2 & 2,04 \\
Saracura & 1 & 1,02 \\
Codorna & 1 & 1,02 \\
Suçuarana & 1 & 1,02 \\
Cachorro do mato & 1 & 1,02 \\
Quati & 1 & 1,02 \\
Onça pintada & 1 & 1,02 \\
\hline TOTAL & 98 & 100,00
\end{tabular}

Fonte: Autoras (2019)

Nota-se que os produtores se justificam a partir do tamanho de seus terrenos, e na maioria dos casos observados a não ampliação da área era devido às necessidades de suas produções e o fomento que suas atividades geram para suas famílias. Os que disseram sim se justificaram através dos seguintes argumentos:

P7. "Porque com a reserva o terreno teria mais qualificação" / P10. "Desde que se tivesse um subsidio do governo" / P20. "Porque faz parte da preservação do meio ambiente".

Percebe-se com isso, que os produtores visualizam a importância da criação de uma reserva florestal, mesmo os que visam um subsidio do governo, pois isso pode estar atrelado ao tamanho do terreno e as necessidades econômicas do produtor, se encaixando para os produtores de pequeno porte, como foi visto através da análise geral dos questionários nesta pesquisa. Mediante isso, foi quantificado que $90 \%$ dos entrevistados afirmam saber a importância que uma reserva florestal possui para a preservação e conservação dos biomas Cerrado e Caatinga.

P2. "Protege a natureza" / P8. "Proíbe o desmatamento e a caça dos animais" / P11. "É importante, muito importante, cuida das plantas nativas da região" / P20. "Ajuda muito, não permite que destruam o meio ambiente da nossa região".

$65 \%$ dos entrevistados disseram que não têm e nem tiveram acompanhamento de órgãos do governo, $30 \%$ disseram que sim e $5 \%$ não opinaram. Também se posicionaram dizendo que não tem incentivo do governo para investir em sua propriedade com um percentual de $85 \%$ dos entrevistados, no entanto $15 \%$ disseram que obtiveram um subsidio do governo mediante o incentivo do Programa de Microfinança Rural do Banco do Nordeste (Agroamigo).

A respeito de como eles classificam seus terrenos, $60 \%$ o definem como conservado e $40 \%$ como preservado, no entanto, $90 \%$ não souberam fazer a distinção entre esses dois termos, afirmando apenas "não sel", enquanto somente $10 \%$ deles citaram como definição para preservação "não mudar a natureza", e para conservação "pode usar os recursos da região, mas não pode destruir". Essas respostas então associadas ao nível de escolaridade dos entrevistados, que foi informado pelos produtores como sendo de nível superior completo. Com isso é notório que o grau de instrução e conhecimento aprofundado pode sim estar associado ao nível de escolarização. O conhecimento popular faz parte da construção de um individuo, porém é 


\title{
REA - Revista de estudos ambientais (Online) v.21, n. 2, p.6-19, jul./dez. 2019
}

imprescindível a ampliação de conhecimento para assegurar a qualidade dos ambientes que tanto se busca como seres racionais que sabem da importância deles para a nossa existência.

Mesmo a maioria não apresentando um conhecimento aprofundado sobre preservação ambiental, $100 \%$ dos entrevistados disseram que se consideram pessoas que se preocupam com o meio ambiente, relatando as seguintes ações:

P2. "Evito queimadas, mantenho as árvores e proíbo a caça" / P9. "Planto árvores, preservo os animais silvestres que habita nossa região" / P12. "Comunico com as outras pessoas a esse respeito, não destruo as árvores e fontes de água" / P15. "Evito o desmatamento, as queimadas, incentivo a reciclagem e o uso consciente da água" / P16. "Uso os resíduos da vegetação como adubo orgânico, cuido dos animais silvestres".

Desta forma, o posicionamento dos entrevistados permite perceber que as ações desenvolvidas pelos produtores situados no entorno das áreas da Serra dos Montes Altos, com propriedades no município de Guanambi-BA, apresenta grande valia para a preservação do patrimônio ambiental, pois no cotidiano desenvolvem maneiras de contribuir com a preservação ambiental, forma tradicional de por em prática seu conhecimento para minimizar os danos que as atividades agropecuárias podem causar nos ecossistemas dos biomas Cerrado e Caatinga.

\section{Conclusões}

Pode-se concluir que os produtores rurais apresentam um grau de entendimento acerca do ambiente em que vivem, pautados em um conhecimento que os permite interagir com o meio e desenvolver suas atividades agropecuárias. No entanto, é notório que existe a necessidade de implementação de ações educativas no contexto do cuidado $e$ uso sustentável do meio de forma mais ampla e eficiente, para que esses produtores possam continuar usufruindo dos recursos naturais de maneira que se assegure 0 equilíbrio entre a agropecuária e o meio ambiente, pois a maioria dos produtores se posicionou dizendo que as atividades agropecuárias não geram danos ao ambiente.

Todavia, a grande maioria dos produtores rurais mostrou conhecer a importância do manejo e conservação da biodiversidade local, porém faltam-lhe maiores incentivos e subsídios para que eles possam ampliar suas interpretações a respeito dos impactos causados pelas atividades agropecuárias, buscando uma maior valorização e conservação dos biomas em que estão inseridos.

\section{Perception of rural producers on the environmental impacts caused by agricultural activities in the municipality of Guanambi-Bahia}

\begin{abstract}
The present work aims to investigate the knowledge of rural producers about the impacts that agricultural activities can cause in the surrounding areas of Serra dos Montes Altos, Guanambi-BA, focusing their concerns and actions on the management and conservation of biomes present there. The methodology was based on the perception of environmental impacts, supported by the method of individual contour through a questionnaire divided into three dimensions: profile of the producer and the area studied; impacts of agricultural activities on the environment; management / conservation / preservation relationship of the Cerrado and Caatinga biomes. To evaluate the dimensions, the content analysis method was used, which consists of analyzing the subjects' statements in a content description process, as well as the percentage method, which consists of grouping the information through similarity. The data analysis allowed to indicate a significant degree of knowledge of the producers about the importance of the environmental preservation, however, the majority do not know the damages that the agricultural activities can generate to the environment. Thus, it is necessary to implement educational policies with these producers in order to guide them to the use of natural resources in order not to compromise the environmental quality of the area.
\end{abstract}

Keywords: Environment; Diagnosis; Knowledge; Human being. 
REA - Revista de estudos ambientais (Online)

v.21, n. 2, p.6-19, jul./dez. 2019

\section{Referências}

ARAUJO, M. L. M. N. Impactos ambientais nas margens do Rio Piancó causados pela agropecuária. Revista Brasileira de Gestão Ambiental. v.4, n.1, p. 13-33, 2010.

ARF, O; BOLONHEZI, A.C. Apostila de Agricultura Geral. Ilha Solteira, SP, 2012. (Apostila).

ARNHOLD, M. F.; RITTER, A. F. S.; BALBINOT, $M$. Benefícios do sistema de rotação de culturas. In: $3^{\circ}$ Simpósio de Agronomia e Tecnologia em Alimentos, Itapiranga, 2016.

AZEVEDO, L. F.; SILVA, S. N. Educação ambiental na interface da Educação do Campo. In: VIII EPEA - Encontro Pesquisa em Educação Ambiental, Rio de Janeiro, 2015.

BARDIN, L. Análise de Conteúdo. Lisboa, Portugal. Edições 70, LDA, 2009.

BRITO, T.; MARX; LUKÁCS: a relação sociedade e natureza. In: COLÓQUIO MARX E ENGELS 6, 2009, Campinas, SP. 2009. p. 1-9

CAMPOS, E. M. Scarabaeidae (Coleoptera) na Caatinga baiana: Distribuição e Planejamento de pesquisas. 2012. Dissertação (Programa de PósGraduação em Modelagem em Ciências da Terra e do Ambiente) - Universidade Estadual de Feira de Santana, Feira de Santana, 2012.

CASAGRANDE, A. E. SOUZA, E. B. C. O espaço e a demografia: o planejamento regional em perspectiva nas margens paranaenses do Lago de Itaipu. Sociedade e Território, Natal, v. 24, n. 1, p. 2-27, 2012.

COSTA, J. N. M. N.; DURIGAN, G. Leucaena leucocephala (Lam.) de Wit (Fabaceae): invasora ou ruderal?. Revista Árvore, Viçosa-MG, v.34, n.5, p.825-833, 2010.

CRUZ, J. C.; FILHO, I. A. P.; PIMENTEL, M. A. G.; COELHO, A. M. KARAM, D.; CRUZ, I.; GARCIA, J. C.; MOREIRA, J. A. A.; OLIVEIRA, M. F.; NETO, M. M. G.; ALBUQUERQUE, P. E. P.; VIANA, P. A.; MENDES, S. M.; COSTA, R. V.; ALVARENGA, R. C.; MATRANGOLO, W. J. R. Circular Técnica Embrapa. Sete Lagoas, 2011. (Apostila).

DIAS-FILHO, M.B. Produção de bovinos a pasto na fronteira agrícola. In: RODRIGUES, K.F.; FERREIRA, W.M.; MACEDO JR., G. de L (Org.). Zootec2010-XX Congresso Brasileiro de Zootecnia - Anais das Palestras. Palmas, Anais. Palmas: Editora, 2010. p. 131-145.

DODONOV, P. Cachorro-vinagre (speothos venaticus) e educação ambiental: Subsídios para o desenvolvimento de atividades, Revbea, Rio Grande, v.6, p.48-51, 2011.
FERREIRA, A. C. S. B. Educação Ambiental: a Ecologia e as atitudes para a Sustentabilidade. 2007. Dissertações (Mestrado em Biologia para o ensino) - Faculdade de Ciências da Universidade do Porto, Portugal, 2007.

GARIGLIO, M. A.; SAMPAIO, E. V. S. B.; CESTARO, L. A.; KAGEYAMA, P. Y. Uso sustentável e conservação dos recursos florestais da caatinga. Brasília: Serviço Florestal Brasileiro, 2010. 368p.

IBGE. Instituto Brasileiro de Geografia e Estatística. Censo Demográfico. Rio de Janeiro, p.1-777, 2006.

INEMA. Instituto do Meio Ambiente e Recursos Hídricos. Parque Estadual da Serra dos Montes Altos. Salvador, 2017. Disponível em: http://www.inema.ba.gov.br/parque-estadual-daserra-dos-montes-altos/. Acesso em: 20 set. 2017.

LEAL, I. R.; SILVA, J. M. C.; TABARELLI, M.; LACHER JR. T. E. Mudando o curso da conservação da biodiversidade na caatinga do Nordeste do Brasil. Megadiversidade, Belo Horizonte, v.1. n.1, p.139-146, jul. 2005.

LEITE, S. P.; SILVA, C. R; HENRIQUES, L. C. Impactos ambientais ocasionados pela agropecuária no Complexo Aluízio Campos. Revista Brasileira de Informações Científicas. v.2, n.2, p.58-64. 2011.

LUCENA, M. M. A. Percepção ambiental por uma comunidade rural do Entorno de uma reserva particular do patrimônio Natural (RPPN), semiárido brasileiro. 2010. Dissertação (PósGraduação em Desenvolvimento e Meio Ambiente) - Universidade Federal do Rio Grande do Norte, Natal. 2010.

MARENGO, J. A. Água e mudanças climáticas. Instituto de Estudos Avançados da USP. Academia Brasileira de Ciências, 2008.

MARIANO, Z. F.; SCOPEL, I.; PEIXINHO, D. M.; SOUZA, M.B. A Relação Homem-Natureza e os Discursos Ambientais. Revista do Departamento de Geografia - USP, v. 22, p. 158-170. 2011.

MATTOS DE DEUS, R; BAKONYI, S. M. C. O impacto da agricultura sobre o meio ambiente. Rev. Elet. em Gestão, Educação e Tecnologia Ambiental. v. 7, n. 7, p. 1306-1315, 2012.

MELO, M. D.; FARIAS, J. L. S.; FERNANDES, F. E. P.; POMPEU, R. C. F. F.; SOUZA, H. A. Caracterização de Atividades Agropecuárias de Comunidades do Semiárido Sobralense Participantes do Projeto Cabra Nossa de Cada Dia. In: I Simpósio Brasileiro de Recursos Naturais do Semiárido - SBRNS, Iguatu, 2013.

MIRANDA, C. A Utilização de Agrotóxicos nos Municípios de Jataí e Perolândia (Go): 


\section{REA - Revista de estudos ambientais (Online) v.21, n. 2, p.6-19, jul./dez. 2019}

Embasamento Legal e Impacto na Saúde PÚBLICA. Dissertação (Programa de PósGraduação em Geografia) - Universidade Federal de Goiás, Jataí. 2016.

MOREIRA, J.N.; LIRA, M.A.; SANTOS, M.V.F. et al. Caracterização da vegetação de Caatinga e da dieta de novilhos no Sertão de Pernambuco. Pesquisa Agropecuaria Brasileira, v.41, n.11, p.1643-1651, 2006.

MORIMOTO, C.; SALVI, R. F. As Percepções do Homem sobre a Natureza. In: 12 Encuentro de Geógrafos de América Latina, Caminando en una América Latina en transformación, Montevidéu, 2009.

NOGUEIRA, M. A. M. Ephemeroptera (Insecta) do Parque Estadual da Serra dos Montes Altos, Bahia, Brasil. 2014. Dissertação (Programa de Pós-Graduação em Sistemas Aquáticos Tropicais) - Universidade Estadual de Santa Cruz, Ilhéus, 2014.

OLIVEIRA, L; MACHADO, L.M.C.P. Percepção, cognição, dimensão ambiental e desenvolvimento com sustentabilidade. In: VITTE, A.C; GUERRA, A.J.T. Reflexões sobre a Geografia física no Brasil. Rio de Janeiro: Bertrand Brasil, p. 129-152, 2004.

OLIVEIRA, M. J. G. S. MEIO AMBIENTE E ECODESENVOLVIMENTO RURAL: O impacto do desenvolvimento rural sobre o meio ambiente. $2012 . \quad$ Disponível em: https://www.uniara.com.br/legado/nupedor/nupedo r_2012/trabalhos/sessao_6/sessao_6B/05_Maria_ Oliveira.pdf. Acesso em: $\overline{1} 5$ jan 2017.

PEREIRA, G. A. O impacto da agropecuária no meio ambiente: retrospectiva histórica e projeção para o futuro. Monografia (Bacharelado em Ciências Contábeis) - Universidade Federal de Rondônia, Cacoal, 2007.

QUADROS, A. Educação ambiental: iniciativas populares e Cidadania. 2007. Trabalho de conclusão de curso (Especialização em
Educação Ambiental (CPGEA) - Universidade Federal de Santa Maria, Santa Maria.

REIGOTA, M. O que é educação ambiental. $2^{\mathrm{a}}$ ed. São Paulo: Brasiliense, 2009. Revista Verde de Agroecologia e Desenvolvimento Sustentável. v. 10, n.3, p 07-12, 2015

SAMBUICHI, R. H. S. et al. A sustentabilidade ambiental da agropecuária brasileira: impactos, políticas públicas e desafios. Rio de Janeiro: IPEA, 2012.

SANTOS, M. J. D.; SILVA, B. B. D.; OLIVEIRA, E. M. D. Analogia entre desmatamento e êxodo rural no nordeste do Brasil. Revista Eletrônica, v.8, n. 1, 2009.

SEMA. Secretaria Do Meio Ambiente. Parque Estadual da Serra dos Montes Altos. 2011.

SILVEIRA, E. P. Florística e Estrutura da Vegetação de Cerrado Sensu Stricto em Terra Indígena no Noroeste do Estado de Mato Grosso. 2010. Dissertação (Programa de Pós Graduação em Ciências Florestais e Ambientais) Universidade Federal de Mato Grosso, Cuiabá. 2010.

TASSO, M. A. L. Caracterização dos sedimentos superficiais e avaliação ambiental da Serra de Monte Alto entre os municípios de Palmas de Monte Alto e Sebastião Laranjeiras, BA. 2012. Dissertação (Doutorado em Geociências e Meio Ambiente) - Universidade Estadual Paulista Júlio de Mesquita Filho, Rio Claro. 2012.

TASSO, M. A. L.; CHANG, M.R.C. Análise Erosional da Serra de Monte Alto entre Palmas de Monte Alto e Sebastião Laranjeiras, BA. Acta Geográfica, v.7, n.14, p.107-121, 2013.

VELOSO, R. B.; RANGEL FILHO, A. L. R.; LIMA, J. C. A. Classificação da vegetação brasileira, adaptada a um sistema universal. IBGE, Rio de Janeiro. 1991. 